\title{
Bongheat, Égliseneuve-près-Billom et Mauzun
}

Jessica Imbert

URL : http://journals.openedition.org/adlfi/4944

ISSN : 2114-0502

Éditeur

Ministère de la culture

\section{Référence électronique}

Jessica Imbert, « Bongheat, Égliseneuve-près-Billom et Mauzun », ADLFI. Archéologie de la FranceInformations [En ligne], Auvergne, mis en ligne le 01 mars 2006, consulté le 03 mai 2019. URL : http:// journals.openedition.org/adlfi/4944

Ce document a été généré automatiquement le 3 mai 2019.

(c) Ministère de la Culture et de la Communication, CNRS 


\title{
Bongheat, Égliseneuve-près-Billom et Mauzun
}

\author{
Jessica Imbert
}

Identifiant de l'opération archéologique : 2006/238

Date de l'opération : 2006 (PI)

1 Cette prospection inventaire diachronique, sur les communes de Bongheat, Égliseneuveprès-Billom et Mauzun, qui s'intègre dans un master 1 d'archéologie à l'université BlaisePascal de Clermont-Ferrand, a pour but à terme de donner une idée plus précise du peuplement de cette région du bas Livradois, qui n'a connu, à ce jour, aucune recherche de ce type. Ce travail, surtout axé sur la Préhistoire, doit également permettre de mieux comprendre certains aspects du comportement humain concernant l'approvisionnement en matières premières lithiques.

2 Lors de cette première campagne automnale, seules quelques parcelles labourées ont été prospectées, mais les résultats sont déjà encourageants pour la suite, puisque quinze sites ou indices de sites préhistoriques (Fig. ${ }^{\circ} 1$ : Bongheat "Les Côtes": matériel lithique recueilli en prospection; 1,2,3,4 et $6:$ lamelles ; 5 : fragment de lame retouchée ; $7:$ lame retouchée ; $8:$ lame) et (Fig. $\mathrm{n}^{\circ} 2$ : Égliseneuve-près-Billom «Champlong »: matériel lithique recueilli en prospection; 1,3 et $4:$ nucleus à lames; 2 : nucleus à lamelles) ont été recensés et un pour l'Antiquité. Il faut toutefois souligner que bien souvent le nombre réduit de vestiges, exclusivement lithiques pour la Préhistoire empêche de donner une datation fiable. Cependant, il semble que quelques sites puissent être datés du Mésolithique, ce qui, si ce fait se confirme, pourrait s'avérer intéressant dans un secteur, où une telle période n'est pas ou peu connue.

3 Jessica Imbert 


\section{ANNEXES}

Fig. $\mathrm{n}^{\circ} 1$ : Bongheat "Les Côtes" : matériel lithique recueilli en prospection ;

$1,2,3,4$ et 6 : lamelles ; 5 : fragment de lame retouchée ; $7:$ lame retouchée ; 8 : lame
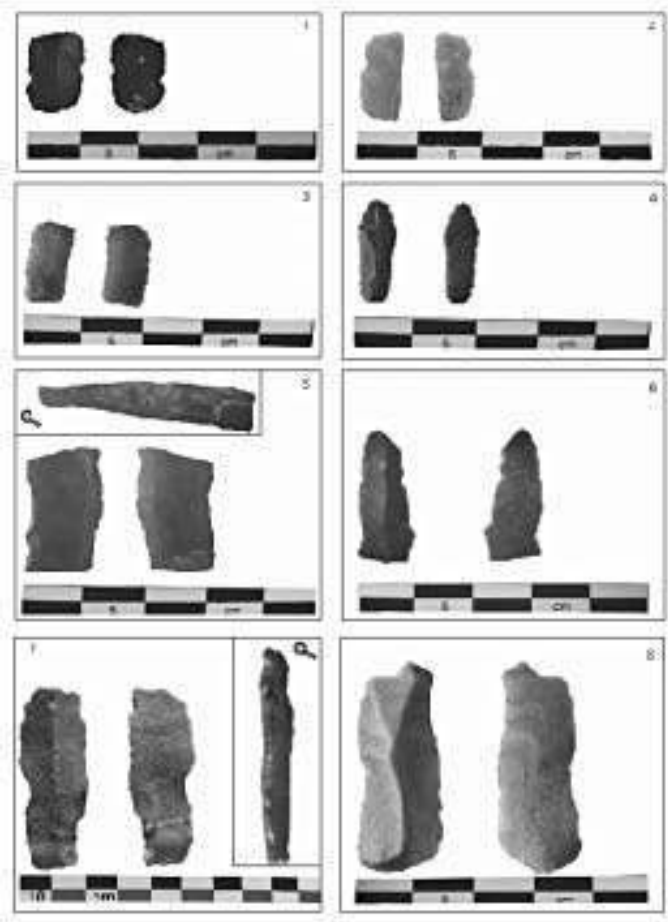

Auteur(s) : Imbert, Jessica (BEN). Crédits : Imbert Jessica, BEN (2006) 
Fig. $\mathrm{n}^{\circ} 2$ : Égliseneuve-près-Billom « Champlong »: matériel lithique recueilli en prospection ; 1,3 et $4:$ nucleus à lames ; 2 : nucleus à lamelles

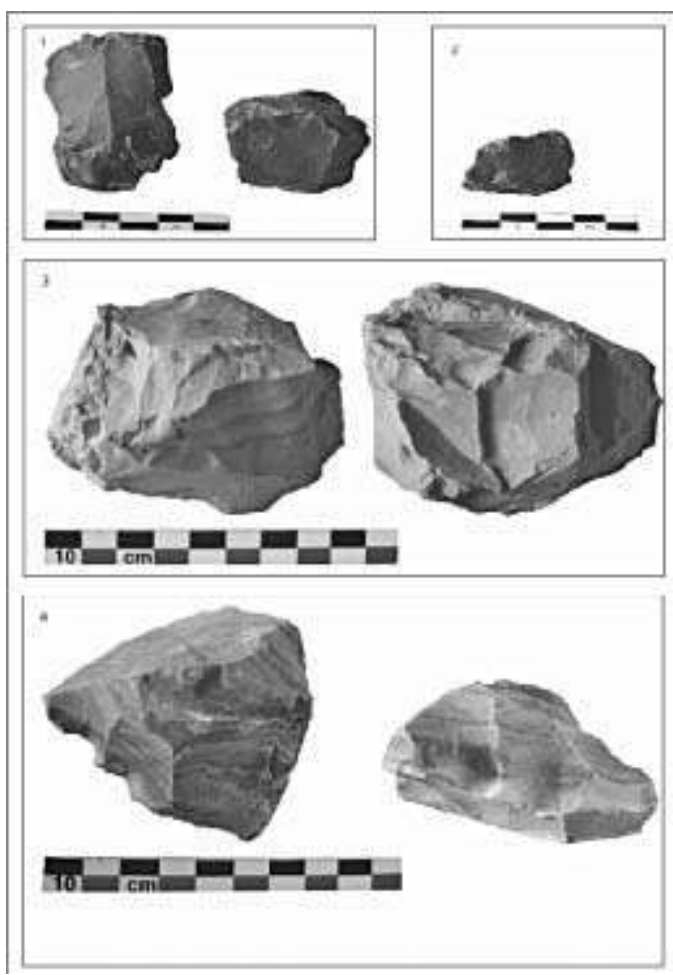

Auteur(s) : Imbert, Jessica (BEN). Crédits : Imbert Jessica, BEN (2006)

INDEX

Index géographique : Auvergne, Puy-de-Dôme (63), Bongheat

Thèmes : approvisionnement, industrie lithique, matière première, peuplement operation Prospection inventaire (PI)

Index chronologique : Empire romain, Mésolithique

\section{AUTEURS}

\section{JESSICA IMBERT}

BEN 